\title{
Study on Influence of Macro-trauma Injuries on the Psychology of a Sportsman
}

\author{
Dr. Wahidur Rahman Khan ${ }^{1}$ (D) Md. Mahfuzur Rahman Khan ${ }^{2}$ (D) Kona Basak $^{3}$ (D) \\ 'Lecturer, Ad-Din Women's Medical College \& Hospital, Bangladesh \\ ${ }^{2}$ Institute of Social Welfare \& Research, University of Dhaka, Bangladesh \\ ${ }^{3}$ Department of Pharmaceutical Sciences, North South University, Bangladesh
}

$\square$ Corresponding Author: Md. Mahfuzur Rahman Khan, E-mail: mahfuzur.rkm@gmail.com

\author{
ARTICLE INFORMATION \\ Received: December 8-25, 2020 \\ Accepted: February 14, 2021 \\ Volume: 1 \\ Issue: 1 \\ DOI: $10.32996 /$ jspes.2021.1.1.2
}

\section{KEYWORDS}

Sport psychology, Sports injuries, Sportsperson \& Sport for All.

\section{ABSTRACT}

This study presents the influence of macro trauma also known as a large-scale injury on the psychology of a sportsman, which may have been happening over some time going before the certified affirmation that injury is obvious. By macro trauma sports injury, individual, and social qualities, may compellingly affect the harmed sportsmen. Wounds, while ideally rare, are regularly an unavoidable piece of game support. While most macro-trauma injury wounds can be dealt with practically zero disturbance ingame support and different exercises of everyday living, some force a significant physical and mental weight. An idiopathic etiology where the purpose behind brokenness is dark may extend vibes of disappointment, shock, and distress, especially if the hurt contender cannot promptly the point of convergence of recuperation, besides, set conspicuous destinations. For the study of the cases, convenience sampling is applied for selecting focus-group participants and for interviews 40 were approached and asked for their participation according to their availability. The findings of the study stated that, for the sportspersons, the mental reaction to a macro trauma injury could trigger or expose genuine psychological wellness issues like melancholy, uneasiness, confused eating, and substance use or misuse. At the point when a sportsman is harmed, a typical passionate response incorporates preparing the clinical data about the injury given by the clinical group, just as adapting sincerely to the macro trauma injury.

\section{Introduction}

Macro-trauma injury results from a striking scene when the sportsman sees that an actual issue has occurred. Mental causes (i.e., awful beneficial encounters) may lead past physical and natural elements to the probability of athletic injury. Such a character is "touchy to injury." The conceivable macro-trauma injury of sportsmen does not dependably envision character-related components and other mental factors alone. Mental elements incorporate execution inspirations, positive working organization, and access of assets though character factors incorporate self-assessment, introspection, compulsiveness, and so forth Notwithstanding, a connection between one mental viewpoint and the probability of large scale injury for sportsmen has consistently appeared. Sportsmen anticipated a huge number of passionate responses and pressing factors while injured. There is no anticipated enthusiastic arrangement for sportsmen who are influenced by macro-trauma injury. They will attempt to comprehend macro-trauma injury-related clinical information, adapt to the wounds, and react. Exercise and athletic training are the fundamental methods for overseeing and tending to mental issues for some sportsmen. In such sportsmen, the enthusiastic commotion may prompt macro-trauma injury. Macro-trauma injury mental responses incorporate injury, dejection, and disturbance, motivation hardship, outrage, bothering, hunger changes, rest interruption, and disincentive. For a sportsman's macro-trauma injury recuperation, mental history, and enthusiastic reaction have a significant influence. Harmed sportsmen go through a total recuperation bundle, which includes addressing these difficulties with less pressure. Besides, a few investigations have proposed the utilization of helpful strategies like objective definition, idealistic self-rootedness, enthusiastic rebuilding, and faster recovery/representation. These strategies can help mitigate despondency and fortify social support and adapting abilities.

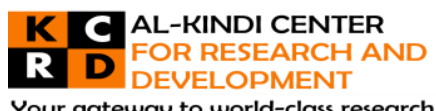

Your gateway to world-class research

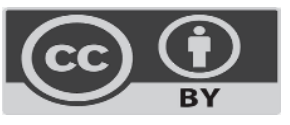

Published by Al-Kindi Center for Research and Development. Copyright (c) the author(s). This open access article is distributed under a Creative Commons Attribution (CC-BY) 4.0 license 
In macro-trauma injury-related injury, the explanation behind desolation and brokenness is quickly perceived and this may help the hurt rival in dealing with even more enough with mental reactions during the serious injury stage and reclamation. In the macro-trauma injury circumstance, various extended lengths of continuously growing torture and reducing execution do not mull over the dispersal of resultant suppositions and might be impressively impenetrable to mental intercessions. The examples of unmistakable sportsmen who have used games psychology research organizations during their own powerful actual issue recuperation experience might be shared to help placate other sportsmen' mindsets toward sport-psychology interventions. Until this point, as expected, in any case, little affirmation has been given to the potential for variable reactions to these two special onsets moreover, etiologies of injury.

\section{Theoretical Framework}

Injured sportsmen need to learn and interpret knowledge about macro trauma injury, often in circumstances of emotional upheaval. The recuperation and recovery process for micro-trauma is variable due to the characteristics of the macro-trauma damage, its therapies, complications, and psychological problems. The wounded sportsmen must know the reasons for injuries. Sportsmen are affected by macro trauma injuries and most of these reactions are transitory. Injured sportsmen also have a variety of feelings, which make it difficult to develop relationships and create confidence with sportsmen. One hazardous response is when harmed understudy sportsmen confine their caloric admission since they feel that since they are harmed, they "don't merit" to eat. Such a response can be a trigger for scattered eating. At the point when an understudy athlete is in danger for scattered eating, this risky response just uplifts the probability these undesirable practices will decline. Another risky reaction to macro trauma injury is misery, which amplifies different reactions and can likewise affect recuperation. Sorrow in some understudy sportsmen may likewise be identified with execution disappointment.

\section{Methodology}

This is explorative research and qualitative data has been used for conducting the research. As qualitative research assists with delivering definite discoveries where no past or auxiliary information is accessible and assists with creating discoveries past the quick edges of the particular investigation (Mack, et. al., 2005); therefore, to gain a stronger understanding of the underlying insights of influence of macro trauma also known as a large-scale injury on the psychology of a sportsman. A face-to-face interview method was followed by using an unstructured questionnaire to conduct the survey. The participants were recruited based on certain characteristics (Crossman, 2020) with the help of convenience sampling. The total sample group was divided into two main clusters e.g., Cluster -A: A total number of 15 women athletes, performing at regional level \& Cluster -B: A total number of 25 male sportspersons, performing at state level. Timeframe of the study was from July 2020 to December 2020.

\section{Literature Review}

Macro trauma refers to tissue damage resulting from a single injury (Medical Dictionary for the Health Professions and Nursing, 2012). The essential issues meddling with this coordinated examination identify with the normalization of phrasing, comprehension of the multifactorial idea of sports injury, and timing of mediation or study. Factors such as personality, social, physical, and psychological influences all shape the injury of macro trauma, and stress play a vital role to play. Social influences are linked to the idea that sports of pain and macro-trauma are very much appreciated in many societies; an indication of dedication and vigor. The physical causes can include muscle imbalances, over workout, and physical exhaustion. This continues to happen in the women's sports sector, with women sportsmen disregard any discomfort incurred by macro trauma injuries and refuse to suffer them (Liston et.al. 2006). Investigations into the relationships between sports accidents and personality are still underway, but personality influences such as confidence, resilience, self-esteem, and fear appear to play an important role in the relationship between stress-macro-trauma. For eg, a sportsman with a high level of fear may be more vulnerable to macro trauma than those with a low level of concern (Ford et.al. 2000). Stressful sportspeople like competitiveness and tough preparation will raise the risk of macro-trauma injury based on the sportsmen's coping mechanisms or place the condition at risk. Most theories rely on stress for neurological causes as a cause of macro-trauma injury. If we feel a traumatic experience, our levels of anxiousness rise, triggering several shifts in concentration and muscle stress and therefore a greater risk of macro trauma. Sportsmen with a psychological capacity to accomplish goals and coping strategies can better deal with stress; minimizing the risk of damage and the real stress of macro-trauma injury should it occur. In addition to that, we can go too far that depression is not only synonymous with macro-trauma, but can also affect physical problems induced by the combination of physical and physical activity. (Petrie \& Perna, 2004). This may explain how certain sportsmen contract illnesses, respond poorly to exercise or express different physical symptoms while they feel overwhelmed. Stress is the major history of sports accidents and we can infer that sportsmen with a higher degree of living stress - like missing a dear one, moving to a new house, or financial difficulties - suffer more injuries. Trainers and athletic counselors should look after these dangerous users. The most critical cause of stress in terms of rehabilitating against macro-trauma injury is not the direct physical trauma impact, but rather the psychological responses to it. This may be the apprehension that they will get wounded once again, feeling desperate, lack treatment, and as if they often have to give up their professions. 
Even if most people respond to macro-trauma normally, the speed and ease of recovery will also differ greatly. In recent years, several developments in the recovery of sportsmen injuries have been made, including the use of more aggressive recuperation, less invasive procedures, and weight education. In the transition from a macro injury to the sport, additional therapeutic approaches are being evaluated. Different forms of motivations were analyzed and the main tool for contributing to the sports arena was intrinsic motivation. Generally, inherent motivation is related to a better understanding of the sport, enhanced emotional resilience, and increased motivation. This is especially obvious when endeavors are made to compare the seriousness of injury among sportsmen, comprehend torment discernment and articulation, characterize courses of events to recuperation, and incorporate mending properties in the grid.

\section{Outcomes and Analysis}

Sportsmen who are having a risky mental reaction to injury might be hesitant to look for treatment. They might be hesitant to uncover their side effects, may consider looking to be as an indication of shortcoming, might be acquainted with working through torment, may have a feeling of qualification and never needed to battle, and might not have created sound ways of dealing with stress to managing disappointment. In addition, numerous understudy sportsmen have not built up their character outside of that as an athlete. Accordingly, if this job is undermined by injury or ailment, they may encounter a critical "misfortune." Getting an understudy athlete to consider treatment can be testing (and it is convoluted by protection issues), so mentors, athletic coaches, and group doctors as the encouraging group of people for the understudy athlete should cooperate to give quality consideration. As an athletic coach or group doctor, it's essential to know about regular signs and indications for different emotional wellness issues and comprehend the assets accessible to treat them. Those faculty likewise should do all that could be within reach to "demystify" psychological well-being issues and permit understudy sportsmen to comprehend that manifestations of emotional wellness issues are as essential to perceive and treat as side effects for other clinical issues and musculoskeletal issues. At the point when understudy sportsmen support huge wounds, for example, knee wounds related with time misfortune from sport, they could endure both just as genuinely with a lessening in their satisfaction. For instance, a respondent from Cluster $-\mathrm{A}$, a woman gymnast mentioned:

"I went right to the absolute bottom. I never figured I could at any point experience anything like that in my life. It was a blend of the decaying of my legs, the new scars, and feeling like a confined creature." (Sukriti, 27)

Underscoring the accessibility of sports medication staff to accommodate early reference and the board of psychological wellbeing issues is fundamental. It is additionally significant for mentors, athletic coaches, and group doctors to help harmed understudy sportsmen and do what they can to keep sportsmen included and part of the group. This may incorporate keeping understudy sportsmen drew in, and simultaneously reassuring them to look for help and do whatever it takes not to "extreme their way through" circumstances that incorporate emotional wellness factors. This is frequently unimaginably supportive in urging sportsmen to look for care. Having programs accessible to teach understudy sportsmen just as sports medication and regulatory staffs in regards to the assets accessible and the significance of communitarian programming gives proper consideration. It is critical to comprehend the emotional wellness assets accessible on every grounds and consider both early references just as setting up multidisciplinary groups that incorporate athletic coaches, group doctors, clinicians, therapists, and other medical care suppliers to give care to psychological well-being issues in understudy sportsmen. If this can be joined into the general objective of improving execution, alongside nourishment and strength and molding, it could be better gotten by sportsmen and mentors, subsequently expanding the consistency with the board and treatment.

\section{Findings}

The findings of these study results, listening to the sportsmen is especially important not only for a medical diagnosis but also for an emotional examination and monitoring. An efficient way to evaluate this is to allow the sportsmen to view the knowledge they obtain sportsmen and coaches should also be taught that a macro-trauma condition is better handled separately. The network of sportsmen and supportive social networks is also successful in promoting sportsmen and women. Coaches can also be motivated to help prevent alienation from teammates by disabled sportsmen. Sportsmen have varying degrees of comfort concerning registered providers of mental health. However, sportspeople with interpersonal issues that require care are referred to a certified practitioner of mental services, preferably one with experience dealing with sportsmen. The challenges for referral include general anxiety, reservations over secrecy, and assumptions of others, distrust of symptoms, and misconception of the care of mental wellbeing. Besides, providers' accessibility and insurance problems may be a deterrent to care. Coaches and teamdoctors have an effect and influence on the sportsman's approach towards mental health. Psychological causes have proven a significant history of the onset of sportsmen injuries and are critical for rehabilitating the macro-trauma and eventually stable return-to-play. In treating and organizing the treatment of wounded sportspeople, squad doctors must consider both psychological and physical aspects. What's more, the absence of normalization of examination boundaries regularly undermines the generalizability of results and the augmentation of hypothetical premises into applied circumstances. 


\section{Discussion and Conclusion}

Working in coordination may include, for instance, the athletic mentor or sports psychology expert furnishing the mentor with recommendations concerning how the person may show uphold for the harmed competitor. In a perfect world, the athletic mentor, sport-psychology specialist, and mentor should cooperate with the competitor to deliver an objective setting program for injury recovery and get back to don support. For many endurance sportsmen being injured is a normal part of the sport, which may require a few weeks of working with a physical therapist or at most a short break from participation. However, when the injury is more serious and requires surgery it can quickly become a distressing setback, an event often appraised as impeding progress toward desired goals and for some ending their athletic career. Sportsmen who have suffered macrotrauma injury can likely relate to the psychological consequences discussed in this article and would have benefitted from receiving a psychological intervention, such as goal setting, imagery, or mindful self-compassion following their injury. Sportsmen with prior mental health concerns, as well as sportsmen requiring surgery and a greater absence from participation in sport or physical activity are at greater risk for experiencing lingering mental health concerns following their physical recovery and should be encouraged to seek services from sport psychologists or sport consultants. Sportsmen might be more dangerous for emotional wellness issues in that they are less inclined to look for treatment, might be hesitant to uncover indications, may consider trying to be as an indication of shortcoming, are acclimated with working through torment, may have a feeling of privilege and never needed to battle, or potentially might not have created solid methods for dealing with stress to manage disappointment. Furthermore, numerous sportsmen have not built up their personality outside of that as an athlete and consequently, if this job is compromised by injury or sickness, they may encounter a critical 'misfortune'. As examined beforehand, practice is frequently a break or method for dealing with stress for some sportsmen, so if the injury happens and they cannot work out, it can bring about a risky reaction.

On the off chance that these side effects do not appear to be disappearing, it is essential to investigate whether they may be identified with an emotional well-being issue, for example, discouragement, and not straightforwardly to the actual injury. Sometimes, the mental response to the blackout - instead of the actual blackout - can be the trigger for the downturn. At the point when this is the situation, essentially trusting that the cerebrum will recuperate isn't sufficient: the downturn likewise should be dealt with. Organizing sports psychology and sports injury research presents a stimulating, anyway testing task. A common technique applying definitional measures, fundamental theoretical plan, and set up preparing natural in the two games brain research and sports injury, invigorate in watching out for different circumstances in the assessment. The potential favorable circumstances of sound, intense assessment in psychology of sports injury to hurt sportsmen, tutors, and clinical experts are undeniable. What ought to be head in the arrangement of this investigation, by and by, is the prerequisite for a psychophysiological foundation on which slanting parts to wear injury, exceptional mental reactions to injury, mental progression through long stretch recuperation, and torture are assessed a lot. Concurrent with this the psychophysiological approach is the prerequisite for theory-driven intercession studies to help in the upgrade of pernicious mental reactions to shake injury that will assist with the rebuilding cycle. Studies across the future, remembering the two individuals for sports, would be instrumental in developing the game's injury mental picture. Such planned examinations are best refined by seeing the responsibility of the two games brain research trained professionals and sports injury specialists where agreeable undertakings affirm the multidimensional thought of sports injury and recuperation. Sportsmen react to injury may contrast, and there is no anticipated succession or response. The reaction to injury reaches out from the time following injury through to the post-injury stage and afterward restoration and at last with getting back to action. For most wounds, the sportsmen can get back to preinjury levels of movement. In more genuine cases, in any case, a sportsmen' playing profession might be in question, and the supplier of the medical service ought to be set up to address these issues. The group doctor is eventually answerable for the revisitation of play choice, and tending to mental issues is a huge segment of this choice. It is significant for athletic mentors and group doctors, just as sportsmen, mentors, and executives, to comprehend that enthusiastic responses to injury are ordinary. Nonetheless, tricky responses are those that either does not resolve or deteriorate over the long run or where the seriousness of indications appears to be unnecessary. Instances of hazardous enthusiastic responses are in the going with the table. For the sportsmen with blackout, it is particularly significant - and troublesome - to look for dangerous mental reactions to the injury. Some sportsmen experience passionate manifestations as an immediate aftereffect of the mental injury that can incorporate inclination miserable or fractious.

Funding: This research received no external funding.

Acknowledgments: We acknowledge there was no external funding support; all authors contributed accordingly in every part of the paper.

Conflicts of Interest: There is no conflict of interest from the authors' side. 


\section{References}

[1] Crossman, A. (2020, March 19). What You Need to Understand About Purposive Sampling. ThoughtCo. https://www.thoughtco.com/purposive-sampling-3026727

[2] Ford, I.W., Eklund, R.C., \& Gordan, S. (2000). An examination of psychosocial variables moderating the relationship between life stress and injury time-loss among sportsmens of a high standard. Journal of Sports Sciences, 18(5), 301-312.

[3] Liston, K., Reacher, D., Smith, T., \& Waddington, I. (2006). Managing pain and injury in non-elite rugby union and rugby league: A case study of players at a British university. Sport in Society, 9, 388-402.

[4] Mack,N., Woodsong, C., MacQueen, K. N., Guest, G., \& Namey, E. (2005). Qualitative Research Methods: A Data Collector's Field Guide, Family Health International.

[5] Macrotrauma. (n.d.) Medical Dictionary for the Health Professions and Nursing. (2012). Retrieved February 142021 from https://medicaldictionary.thefreedictionary.com/macrotrauma

[6] Petrie, T.A., \& Perna, F. (2004). Psychology of injury: Theory, research and practice. In T. Morris \& J. Summers (Eds), Sport psychology: Theory, application, and issues (2nd ed., pp. 547-571). Milton, Australia: Wiley. 